\title{
Cluster headache-like disorder in childhood
}

\author{
S McNabb, W Whitehouse
}

\begin{abstract}
This paper reviews the diagnostic features of cluster headache-like disorder and describes its presentation in childhood. Case note summaries of patients with this condition are presented in the context of a brief summary of the literature. Four patients (two girls; aged 12 to 15 years) with cluster headache-like disorder were seen over a period of four years in the paediatric neurology department of Birmingham Children's Hospital. Their histories and clinical courses are described. All had a history of "thrashing around" or bizarre behaviour during attacks, which had distracted attention from the headache and seemed to contribute to delay in diagnosis. It appears that cluster headache-like disorder does occur in childhood but is not common and can be mistaken for other conditions. A history of thrashing around accompanied by headache is very suggestive. Recognition of the symptoms in the general paediatric clinic would allow rapid diagnosis.

(Arch Dis Child 1999;81:511-512)
\end{abstract}

Keywords: cluster headache; pseudoseizures

Cluster headache is well recognised in adults but has been reported only rarely in children. Previous authors ${ }^{12}$ have suggested that, although symptoms may begin in childhood, the diagnosis often goes unrecognised.

The essential diagnostic features are:

- Headache that is severe and strictly unilateral, orbital, supraorbital, and/or temporal

- The duration of headache is $15-180 \mathrm{~min}$ utes if untreated and it occurs between once every other day and eight times a day

- It is associated with one or more of the following: conjunctival injection, lacrimation, nasal congestion, rhinorrhoea, forehead and facial sweating, miosis, ptosis, and eyelid oedema. These must occur on the side of the pain

- Attacks occur in series lasting for weeks or months (so called "cluster" periods) separated by remission periods usually lasting months or years

Department of Paediatric Neurology, Birmingham Children's Hospital, Birmingham B4 6NH, UK

S McNabb

W Whitehouse

Correspondence to: Dr Whitehouse

Accepted 17 August 1999 coexisting disorder, the cluster headache mus not occur initially in close temporal relation to the other disorder. have had at least five attacks.

History and/or neurological examinations and appropriate diagnostic tests must not suggest another classified disorder; if there is a
"Cluster headache-like disorder not fulfilling the above criteria" is defined as: "Headache attacks that are believed to be a form of cluster headache or paroxysmal hemicrania, but which do not quite meet the operational diagnostic criteria for any of the forms of cluster headache or paroxysmal hemicrania."

All but one of the criteria must be met. ${ }^{3}$

\section{Clinical cases}

We report four cases of cluster headache-like disorder (two girls) beginning between the ages of 6 and 15 years. The patients were referred to the neurology department at Birmingham Children's Hospital over a period of four years. The delay to diagnosis from onset of symptoms was from a few weeks to six years.

Each had many attacks of episodic, severe headache associated with autonomic features, which occurred several times a day during clusters. None of the children fulfilled the International Headache Society ${ }^{3}$ criteria for pure cluster headache because the pain was either bilateral or did not occur in the orbital/supraorbital/temporal area (table 1). However the criteria for cluster headache-like disorder were met and examination and investigations (basic biochemistry; ammonia, lactate, organic and amino acid concentrations in blood and urine; electroencephalography; and cerebral imaging) were normal when checked between attacks.

\section{Discussion}

All the children had to wait at least a few months to receive a diagnosis and effectively directed treatment. Thrashing around and bizarre behaviour were prominent features of each child's presentation and were felt to be useful in prompting the diagnosis (table 1). Although they are not diagnostic criteria for cluster headache "motor restlessness" and apparently irrational behaviour are well recognised and common features of the condition, and may be useful both as a diagnostic prompt and in differentiating the condition from-for example, migraine. ${ }^{4}$ It has been suggested that asking patients in clinic to act out their behaviour during an attack might be diagnostically helpful. ${ }^{4}$ In two of our patients, home video recording of attacks was an invaluable and inexpensive aid to diagnosis.

Thrashing around had caused problems for the children: schools tend to be unsympathetic to pupils screaming and being disruptive in the classroom if they do not understand the cause. This might have been a contributing factor to the two boys' expulsions. In one child, motor activity was stereotyped enough to lead to an initial erroneous diagnosis of pseudo seizures. 
Table 1 Patient details

\begin{tabular}{|c|c|c|c|c|}
\hline & Patient 1 & Patient 2 & Patient 3 & Patient 4 \\
\hline Age at onset (years) & 9 & 12 & 15 & 6 \\
\hline Age at diagnosis (years) & 13 & $12-3$ months later & 15 & 12 \\
\hline Location & Frontal (bilateral) & Occipital (unilateral) & Frontal (bilateral) & All over (bilateral) \\
\hline Clustered & Yes & Yes & Yes & Yes \\
\hline Duration & Few minutes & Few to 20 minutes & Few to 20 minutes & Minutes to hours \\
\hline Frequency & Several/day & 3-4/day & $2-3 /$ day & $3-4 /$ day \\
\hline Cycle & Few weeks between attacks & Months between attacks & Months between attacks & Weeks to years between attacks \\
\hline \multirow[t]{2}{*}{ Emotional symptoms } & Yes & Yes & Yes & Yes \\
\hline & Angry screaming & Wailing, rocking & Upset after & Screaming, crying (tries to cut head off) \\
\hline Thrashing around & Yes & Yes & Yes & Yes \\
\hline Flushing & Yes & Yes & $?$ & Yes \\
\hline \multirow[t]{2}{*}{ Autonomic features } & Yes & Yes & Yes & $?$ \\
\hline & Eyes water & Sweaty, swelling, flushing & Eyes and nose run & \\
\hline Personal history of migraine & No & Yes & No & Yes \\
\hline \multirow[t]{2}{*}{ Family history of headache } & Yes & Yes & No & $?$ \\
\hline & Grandmother & Grandmother & & \\
\hline \multirow[t]{2}{*}{ Behavioural problems } & Yes & No & Missed school & Yes \\
\hline & Expelled & & & $\begin{array}{l}\text { Expelled, fostered } \\
\text { ?Psychiatric problems }\end{array}$ \\
\hline Drugs that helped & Pizotifen & $\begin{array}{l}\text { Oxygen, sumatriptan, } \\
\text { ergotamine inhaler, } \\
\text { ?pizotifen, ?verapamil }\end{array}$ & $\begin{array}{l}\text { Oxygen, } \\
\text { ?sumatriptan, } \\
\text { pizotifen }\end{array}$ & $\begin{array}{l}\text { None, benefits } \\
\text { outweighed by side effects }\end{array}$ \\
\hline Outcome & Lost to follow up & $\begin{array}{l}\text { Helped but not cured } \\
\text { with drugs }\end{array}$ & $\begin{array}{l}\text { Helped but not cured } \\
\text { with drugs }\end{array}$ & Lost to follow up \\
\hline
\end{tabular}

Drugs in italics were used for regular prophylaxis, drugs in regular font for rescue treatment of attacks.

If the diagnosis is made, a range of drugs might be effective in the prevention and relief of this excruciatingly painful and distressing condition. Home oxygen, described as "the standard treatment of acute attacks" ${ }^{5}$ was certainly helpful in the two patients who tried it, and it had no adverse effects. Subcutaneous sumatriptan, which has been reported to be effective in $75 \%$ of patients with cluster headache ${ }^{6}$ was of limited use in the two patients who tried it. Newer "triptans" (5-HT $1 \mathrm{~B} / 1 \mathrm{D}$ receptor agonists) have also been effective in some adult patients. All four of these children had some prophylactic effect from pizotifen, only one tried verapamil and had apparent benefit. Because of the unpredictable nature of the condition it is difficult to know whether prophylaxis impacted on the frequency of attacks, although there was no clear impression that this was the case. Its effect seemed rather to lessen the severity of pain during each bout of headaches. Verapamil has not been taken by patient 2 for long enough to demonstrate clear efficacy.

Drugs that might be used to prevent headache in patients with cluster headache include: verapamil, lithium, ergotamine, steroids, serotonin inhibitors, pizotifen, methy- sergide, and antihistamines. Inhaled 100\% oxygen by means of a high flow delivery system with reservoir attached to a tight fitting facial mask; triptans, such as sumatriptan and ergotamine; and intranasal lignocaine (lidocaine) can be effective as acute pain relief. ${ }^{15}$

In summary, the differential diagnosis of cluster headache is wide, and in childhood it may be mistaken for pseudo seizures or some type of behavioural disorder. A history of thrashing around is often reported and, combined with headache, should prompt a search for other features, enabling diagnosis and suitably directed advice and treatment.

1 Neubauer D, Kuhar M, Ranvik IM. Antihistamine responsive cluster headache in a teenage girl. Headache 1997;37:296-8.

2 Ridderikhoff J, Koudstaal PJ. Cluster headache: misjudged because unknown [abstract]. Nederlands Tijdschrift voor Geneeskunde 1997;14:313-15.

3 Headache Classification Committee of the International Headache Society. Classification and diagnostic criteria for headache disorders, cranial neuralgias and facial pain. Cephalalgia 1998;8(suppl 7):1-96.

4 Blau JN. Behaviour during a cluster headache. Lancet 1993; 342:723-5.

5 Ekbom K. Treatment of cluster headache: clinical trials, design and results. Cephalalgia 1995;15(suppl):33-6.

6 Wilkinson M, Pfaffenrath V, Schoenen J, Diener TJ. Migraine and cluster headache-their management with sumatriptan: a critical overview of the current clinical experience. Cephalalgia 1995:15:378-57. 